\title{
THE WOLF FROM GROTTA ROMANELLI: NEW INSIGHTS FROM BRAIN MORPHOLOGY
}

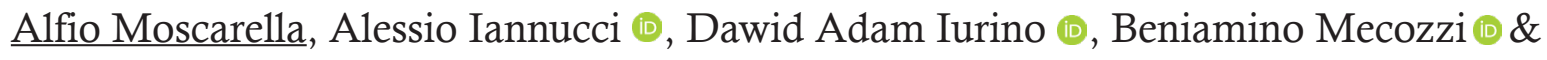 \\ Raffaele Sardella (-)
}

Dipartimento di Scienze della Terra, Sapienza University of Rome, Piazzale A. Moro 5, 00185 Rome, Italy.

\author{
KEYwORDS: \\ Grotta Romanelli; \\ Canis lupus; \\ Brain anatomy.
}

\section{Bullet-Points Abstract}

- The wolf from Grotta Romanelli was initially referred to Canis aureus, subsequently to $C$. mosbachensis or $C$. lupus by other authors.

- Sardella et al. (2014) attributed it to $C$. lupus.

- A detailed neuroanatomical analysis confirmed this attribution and provide new insights on brain anatomy and phylogeny.

\section{INTRODUCTION}

The wolf, Canis lupus, is a widely spread, ecological tolerant and polymorph species. However, the morphological analyses, often the only available approach in the study of the fossil record, normally entails difficulties in defining and estimating the intraand interspecific variability both chronologically and geographically (Sardella et al., 2014) hence resulting in an unsettled taxonomy.

The wolf from Grotta Romanelli (Apulia, Italy) represents an emblematic case study. It was first referred to Canis aureus by Blanc (1928) and then to Canis mosbachensis and Canis sp. by later authors (Caloi and Palombo, 1998; Sardella et al., 2006). Recently, Sardella et al. (2014) attributed the canid remains from Grotta Romanelli (level G) to C. lupus; this attribution was based on the morphological and morphometric analysis of the cranial elements and endocasts, comparing them with other "Apulian wolves" and with C. mosbachensis, C. lupus lunellensis, C. lupus santenaisiensis, C. lupus italicus.

Here, new insights are provided from a detailed neuroanatomical analysis.

\section{MATERIALS AND METHODS}

The complete Canis skull (P3580) from Grotta Romanelli, stored at "Museo delle Civiltà (MUCIV)" (Rome), has been compared with other skulls of extant C. lupus italicus $(\mathrm{n}=6), C$. mesomelas $(\mathrm{n}=1), C$. aureus $(\mathrm{n}=1)$ and $C$. latrans $(\mathrm{n}=1)$, stored in "Dipartimento di Zoologia, Sapienza University of Rome". The specimens were scanned at the "M.G. Vannini" Hospital of Rome (Italy). 3D rendering of the fossil specimens were computed using Osirix 3-9-4 32-bits and 3D Open-Source software Blender 2.63 Intel 32 bits. Geometrical measurements were obtained in Meshlab.

\section{Results AND Discussion}

Canis lupus italicus has a well-defined sulcal pattern with minor individual variations; all the 14 principal sulci (Radinsky, 1973; Lyras, 2009) display the same relative size and orientation. Among the dog-like species such as jackals (Canis adustus, C. aureus, C. mesomelas) wolves (C. lupus, $C$. rufus, $C$. simensis) coyote (C. latrans) dhole (Cuon alpinus) and African hunting dog (Lycaon pictus), only wolves show the longest prorean gyri of the group, together with the presence of three notches in the region rostral to the praesylvian sulcus: the prorean and intraorbital sulci, and a third groove. These features can be therefore considered typical of wolves, and do not seem to be influenced by allometry (Radinsky, 1973; Lyras, 2009). All the specimens of $C$. lupus italicus and the brain from the Grotta Romanelli C. lupus shares the same lupine features supporting the recent re-attribution to $C$. lupus (Sardella et al., 2014). C. mesomelas and C. latrans cranial endocasts are consistent with the previous observations of Radinsky (1973) and Lyras (2009), in that both lack the third sulcus and show a general geometry far divergent from the $C$. lupus-like forms as well as the Apulian wolf. The two graphics show some geometric measurements: the Surface/ Volume ratio (Fig. 1f) and the Prorean Gyrus volume/ Brain volume ratio (Fig. 1g). The first graph describes two major groups: 1) wolves, 2) jackals and coyote. The Prorean gyrus Volume / Encephalic Volume ratio highlights the contribute of the prorean gyrus, showing a more heterogeneous pattern, with 

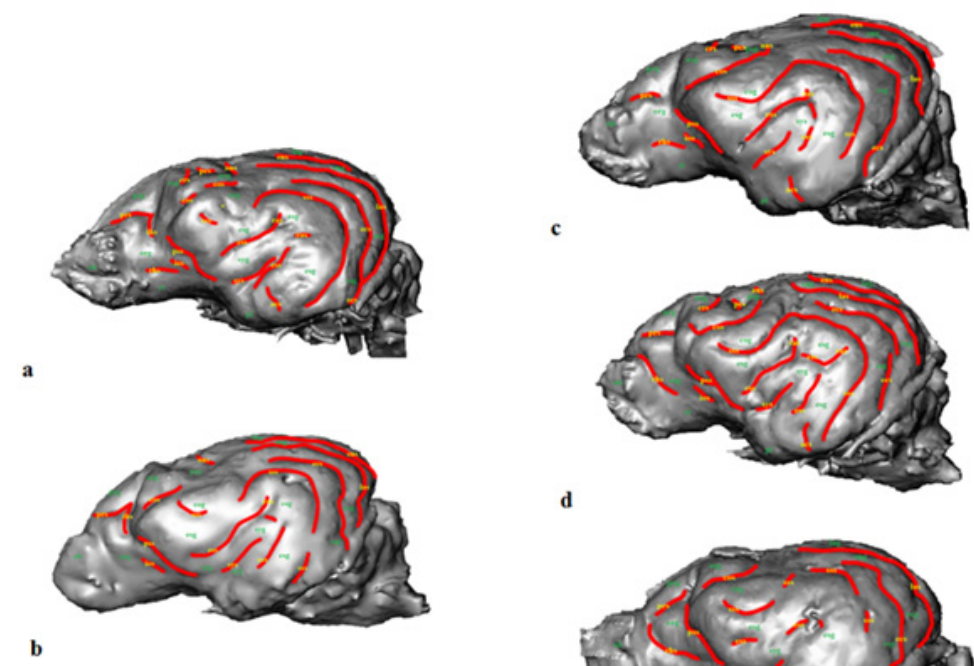

d
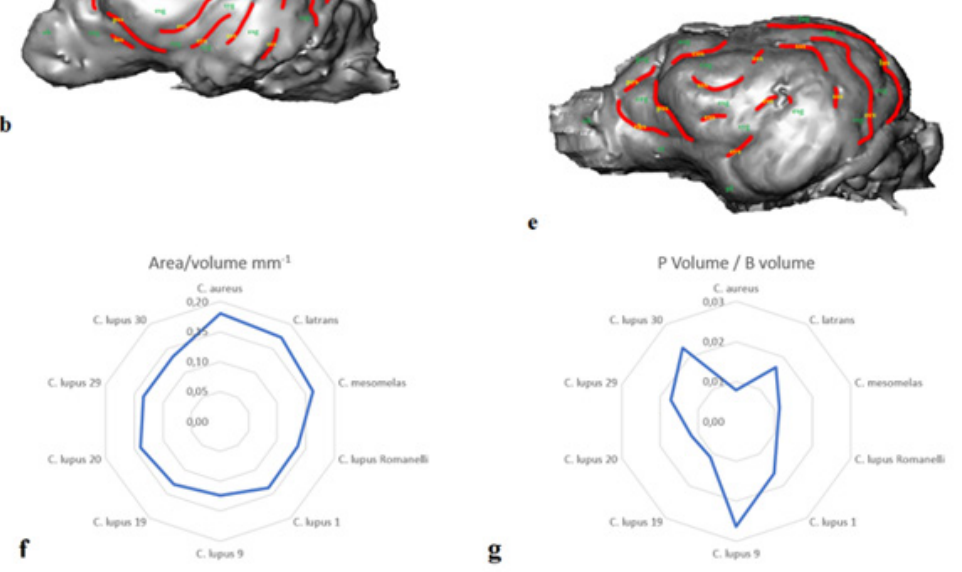

Fig. 1. A-E. Cranial endocasts of: A, Canis lupus italicus; B, Canis from Grotta Romanelli; C, Canis latrans; D, Canis mesomelas; E, Canis aureus. F-G. Graphics of Surface/ Volume ratio and Prorean Gyrus volume/ Brain volume index. Principal sulci in the rostral region: Prs: prorean sulcus; Ths: third groove; Ios: intraorbital sulcus. Principal gyri: Prg: proreal gyrus; Org: orbital gyrus

low values for jackals but, in some cases, close to the wide range of wolves variation.

\section{Conclusion}

Our results suggest that several features typical of the wolves group (Lyras, 2009), such the third sulcus and the length of the prorean gyrus, do not seem to be mutually linked, indeed the third sulcus is also present in samples with a low $\mathrm{P}$ volume/ $\mathrm{B}$ volume index $(C$. lupus 19 and Canis from Grotta Romanelli). Therefore, it is more parsimonious to attribute the presence of the third sulcus to other biological factors specific of the wolf's lineage (as also noted by Lyras, 2009). This confirms the taxonomical attribution of the canid sample from Grotta Romanelli to C. lupus proposed by Sardella et al. (2014).

\section{ACKNOWLEDGEMENTS}

This work was supported by Grandi Scavi 2016 (ref. SA116154CD9592F3), Grandi Scavi 2017 (ref. SA11715C81468801), Grandi Scavi 2018 (ref. SA1181642D3B3C58), Grandi Scavi 2019 (ref. SA11916B513E7C4B) of Sapienza, University of Rome, resp. Raffaele Sardella.

\section{REFERENCES}

Blanc G.A. (1928). Grotta Romanelli II. Dati ecologici e paletnologici. Archivio per l'Archeologia e l'Etnologia, 58: $1-50$.

Caloi L. \& Palombo M.R. (1998). Complessi faunistici e variazioni ambientali nel Villafranchianio-Aureliano medio dell'Italia centrale. Biogeographia, 19: 27-34.

Lyras G.A. (2009). The evolution of the brain in Canidae (Mammalia: Carnivora). Scripta Geologica, 139: 1-93.

Radinsky L. (1973). Evolution of the Canid Brain. Brain, Behavior and Evolution, 7: 169-202.

Sardella R., Palombo M.R., Petronio C., Benedetti C. \& Pavia M. (2006). The early Middle Pleistocene large mammal faunas of Italy: an overview. Quaternary International, 149: 104-109.

Sardella R., Bertè D., Iurino D. A., Cherin M. \& Tagliacozzo A. (2014). The wolf from Grotta Romanelli (Apulia, Italy) and its implications in the evolutionary history of Canis lupus in the Late Pleistocene of Southern Italy. Quaternary International, 328-329:179-195. 